\title{
Regulation of a Putative Neurotransmitter Effect of Corticotropin- Releasing Factor: Effects of Adrenalectomy
}

\author{
Luis A. Pavcovich and Rita J. Valentino \\ Department of Psychiatry, Allegheny University, Philadelphia, Pennsy/vania 19102
}

This study tested the hypothesis that endogenous glucocorticoids regulate a putative neurotransmitter function of corticotropin-releasing factor (CRF) in the locus coeruleus (LC). LC spontaneous discharge and activation by intracerebroventricularly administered CRF, hypotensive challenge, sciatic nerve stimulation, and carbachol were compared in adrenalectomized and sham-operated halothane-anesthetized rats. LC spontaneous discharge was higher in adrenalectomized versus sham-operated rats. Intracoerulear microinfusion of a CRF antagonist decreased LC discharge rates of adrenalectomized rats to rates comparable with those observed in sham-operated rats but had no effect in sham-operated rats. The CRF doseresponse curve was shifted in a complex manner in adrenalectomized rats, suggesting that a proportion of CRF receptors were occupied before CRF administration, and low doses of CRF were additive. Higher doses of CRF produced effects that were greater than predicted by simple additivity. Hypotensive challenge increased LC discharge rates of adrenalectomized rats by a magnitude greater than that predicted on the basis of additivity. In contrast, LC responses to carbachol and sciatic nerve stimulation were similar in both groups. The results suggest that adrenalectomy enhances tonic and stress-induced CRF release within the LC and also alters postsynaptic sensitivity of LC neurons to CRF. Because adrenalectomy also alters release of neurohormone $\mathrm{CRF}$, the present study suggests that CRF actions as a neurohormone and as a neurotransmitter in the LC may be co-regulated. Such parallel regulation may underlie the coexistence of neuroendocrine and noradrenergic dysfunctions in stress-related psychiatric disorders.

Key words: corticotropin-releasing factor; locus coeruleus; adrenalectomy; stress; hypotension; carbachol; norepinephrine; nitroprusside; rats
Corticotropin-releasing factor (CRF) has been hypothesized to act as both a neurohormone and a brain neurotransmitter (Vale et al., 1981, 1983; Rivier et al., 1985; Dunn and Berridge, 1990; Owens and Nemeroff, 1991; Valentino et al., 1993). It is well established that hypothalamic CRF is released into the median eminence, where its actions on anterior pituitary corticotrophs promote secretion of adrenocorticotropin (Vale et al., 1981, 1983; Rivier et al., 1985). The neurotransmitter role of CRF is supported by the widespread distribution of CRF-immunoreactive terminals and binding sites in brain (Swanson et al., 1983; DeSouza et al., 1985; DeSouza, 1987; Sakanaka et al., 1987). Consistent with this, central CRF administration mimics many autonomic and behavioral components of stress responses, even in hypophysectomized animals (Dunn and Berridge, 1990; Owens and Nemeroff, 1991; Valentino et al., 1993). Moreover, central administration of CRF antagonists or antisera prevents several autonomic and behavioral responses elicited by stressors (Brown et al., 1985; Britton et al., 1986; Tazi et al., 1987; Kalin et al., 1988; Swiergel et al., 1992; Tache et al., 1993). Parallel actions of neurohormone and neurotransmitter CRF may coordinate endocrine with autonomic and behavioral components of the stress response.

\footnotetext{
Received June 12, 1996; revised Sept. 6, 1996; accepted Oct. 7, 1996
}

This work was supported by U.S. Public Health Service Grants MH42796 and MH00840 (a Research Scientist Development Award to R.J.V.). We thank Dr. Jean Rivier for the generous gifts of CRF and DPheCRF ${ }_{12-41}$, Dr. Paul McGonigle for comments on data presentation and interpretation, and Dr. Randall R. Sakai for technical advice in performing adrenalectomies. The expert technical assistance of Mr. Bowen Kang and Ms. Wei Ping Pu is appreciated.

Correspondence should be addressed to Dr. Rita J. Valentino, Department of Psychiatry, Allegheny University MS 403, Broad and Vine Streets, Philadelphia, PA 19102-1192.

Copyright $\odot 1996$ Society for Neuroscience $0270-6474 / 96 / 170401-08 \$ 05.00 / 0$
The noradrenergic nucleus locus coeruleus (LC) is one site at which CRF may function as a neurotransmitter (Valentino et al., 1993). This is supported by recent ultrastructural evidence for synaptic contacts between CRF-immunoreactive terminals and LC dendrites (Van Bockstaele et al., 1996). CRF increases LC discharge rates (Valentino et al., 1983; Valentino and Foote, 1988) and norepinephrine release in LC target regions (Lavicky and Dunn, 1993; Page and Abercrombie, 1995; Smagin et al., 1995). LC activation elicited by certain physiological stimuli is prevented or attenuated by microinjection of CRF antagonists into the LC (Valentino et al., 1991; Curtis et al., 1994; Florin et al., 1995). Finally, certain immunological, autonomic, and behavioral responses to stressors can be mimicked by CRF administration into the LC (Butler et al., 1990; Caroleo et al., 1993; Monnikes et al., 1994; Rassnick et al., 1994).

The neurohormone action of CRF is highly regulated by glucocorticoids, which affect CRF synthesis and release (Paull and Gibbs, 1983; Plotsky and Sawchenko, 1987; Bradbury et al., 1991; Dallman et al., 1992). This regulation is demonstrated by the effects of adrenalectomy, which include enhanced CRF synthesis in paraventricular hypothalamic neurons (Sawchenko et al., 1984; Jingami et al., 1985; Young et al., 1986; Imaki et al., 1991) and release into the median eminence (Suda et al., 1983; Plotsky and Sawchenko, 1987; Fink et al., 1988). Previous stress also alters CRF neurohormone function (Dallman et al., 1992). Thus, transcription of CRF mRNA in paraventricular hypothalamic neurons, the number of CRF-immunoreactive neurons in this nucleus, and CRF content in the median eminence are all altered by repeated or chronic stress (Chappell et al., 1986; Imaki et al., 1991; De Goeij et al., 1992; Mamalaki et al., 1992; Bartanusz et al., 1993). 
In contrast to neurohormone CRF, little is known regarding regulation of the putative neurotransmitter actions of CRF. Recent findings from this laboratory indicate that repeated stress sensitizes LC neurons to low doses of CRF (Curtis et al., 1995). The present study was designed to determine whether adrenalectomy selectively affects the putative neurotransmitter function of CRF in the LC. LC spontaneous discharge rate, activation by exogenous CRF, endogenous CRF (via hypotensive challenge), a muscarinic agonist (carbachol), and an excitatory amino acid input (sciatic nerve stimulation) were quantified and compared in adrenalectomized and sham-operated rats in the halothaneanesthetized state.

\section{MATERIALS AND METHODS}

Animals. The subjects were adult male Sprague Dawley rats (Taconic Farms, Germantown, NY) weighing $\sim 300 \mathrm{gm}$ at the beginning of the experiments. Rats were initially housed three to a cage in a controlled environment $\left(20^{\circ} \mathrm{C}, 12 \mathrm{hr}\right.$ light/dark cycle, lights on at 7:00 A.M.). Food and water were available ad libitum.

Adrenalectomy. Surgical adrenalectomy and sham adrenalectomy were performed under pentobarbital $(50 \mathrm{mg} / \mathrm{kg}$, i.p.) anesthesia via the dorsolateral approach. Surgery was done $14 \mathrm{~d}$ before the experiments. Rats were housed individually after surgery, and food was available ad libitum. Sham-operated rats were given water, whereas adrenalectomized rats received drinking water containing $0.9 \% \mathrm{NaCl}$. The completeness of adrenalectomy was determined by assay of plasma corticosterone at the end of the experiment. Experiments were done on two rats a day (1 adrenalectomized and 1 sham-operated), and the order of experiments was alternated on a daily basis.

Surgery. The procedures used for recording LC discharge of halothaneanesthetized rats were similar to those described previously (Valentino et al., 1983, 1986, 1991). Rats were anesthetized with $2 \%$ halothane-in-air mixture administered through a nose cone. The jugular vein was cannulated (PE 100, void volume $70 \mu \mathrm{l}$ ) for infusion of nitroprusside and/or blood sampling. The femoral artery was cannulated for blood pressure recordings. A tracheal tube was inserted, and the halothane delivered through this tube. The anesthetic was maintained at $1 \%$ through the experiment. Body temperature was maintained at $36-37^{\circ} \mathrm{C}$ by a feedbackcontrolled heating pad. Rats were positioned in a stereotaxic instrument using blunt ear bars, and the head was oriented at a $15^{\circ}$ angle to the horizontal plane (nose down). The skull was exposed, and a hole $(\sim 3 \mathrm{~mm}$ diameter), centered at $1.1 \mathrm{~mm}$ lateral to the midline and $3.7-3.9 \mathrm{~mm}$ caudal to the intersection of midline and lambda, was drilled over the cerebellum for approaching the LC. The dura over the cerebellum was carefully removed using fine iridectomy scissors. Another hole was drilled with its center at $1.0 \mathrm{~mm}$ caudal to bregma and $1.5 \mathrm{~mm}$ lateral to the midline for placement of a 26 gauge cannula to be used for intracerebroventricular drug administration. The cannula was positioned $5.6 \mathrm{~mm}$ ventral to the skull surface, placing its tip in the lateral ventricle.

Recording. For most experiments, a glass micropipette pulled to a 2-3 $\mu \mathrm{m}$ diameter tip (4-7 M $\Omega$ ) and filled with $2 \%$ pontamine sky blue (PSB) dye in $0.5 \mathrm{M}$ sodium acetate buffer was used to record LC discharge. This was advanced toward the LC with a micromanipulator. Microelectrode signals were amplified and filtered. Impulse activity was monitored with an oscilloscope and a loudspeaker to aid in localizing the LC. LC neurons were tentatively identified during the recording by their spontaneous discharge rates $(0.5-5 \mathrm{~Hz})$, entirely positive, notched waveforms $(2-3$ msec duration) and biphasic excitatory-inhibitory responses to contralateral hindpaw or tail pinch. When stable, unitary action potentials were isolated; a window discriminator was used to convert the occurrence of each action potential into digital pulses, which were led into a Gateway computer via a CED 1401 Plus interface (Cambridge Electronic Design, Cambridge, UK), using Spike 2 software for on-line visualization and storage and off-line analysis.

For experiments involving intracoerulear administration of CRF or a CRF antagonist, double-barrel glass micropipettes were used to record single-unit LC discharge and simultaneously microinfuse the peptide (Akaoka and Aston-Jones, 1991). These consisted of a recording pipette glued using a photopolymerizing resin (Silux, $3 \mathrm{M}$ ) next to an infusion pipette (Fisher Scientific, Houston, TX). The recording pipette had a 2-4 $\mu \mathrm{m}$ diameter tip (4-7 M $\Omega$ ) and was filled with PSB. The infusion pipette (20-50 $\mu \mathrm{m}$ diameter tip) was angled at $\sim 30-45^{\circ}$, with its tip adjacent to the tip of the recording pipette but $100-120 \mu \mathrm{m}$ dorsal. This was filled with a solution of either CRF $(1 \mathrm{mg} / \mathrm{ml})$ or $\left[D P h e^{12}, \mathrm{Nle}^{21,38}\right.$, $\mathrm{C}^{\alpha} \mathrm{MeLeu}^{37} \mathrm{r} / \mathrm{hCRF}(12-41)\left(\mathrm{DPheCRF}_{12-41} ; 0.33 \mathrm{mg} / \mathrm{ml}\right)$ and connected by PE tubing to a source of solenoid-activated pneumatic pressure (Picospritzer, General Valve, Fairfield, NJ). This infusion pipette was calibrated such that known volumes could be administered (1 mm displacement $=60 \mathrm{nl})$. Intracoerulear infusions were made by applying small pulses of pressure (5-25 psi, $10-30 \mathrm{msec}$ in duration) to the peptide containing barrel at a frequency of $0.2-1 \mathrm{~Hz}$ to deliver a volume of $30 \mathrm{nl}$.

Protocol. In experiments designed to determine the effects of adrenalectomy on LC spontaneous discharge rate and discharge evoked by repeated sciatic nerve stimulation, one to five cells were recorded in a single tract in individual rats. Once an action potential was isolated, spontaneous discharge rate was recorded for at least $6 \mathrm{~min}$. After this, a trial of 60 sciatic nerve stimuli $(1 \mathrm{~mA}, 0.5 \mathrm{msec}$ duration, $0.1 \mathrm{~Hz})$ was initiated. Stimuli were applied through a pair of 25 gauge hypodermic needles inserted into the medial aspect of the contralateral hindpaw, using a Grass stimulator (S88) and stimulus isolation unit (Isoflex, Ampi). LC discharge activity during these trials was recorded and stored as peristimulus time histograms (PSTHs).

For experiments involving intracoerulear infusion of CRF or DPheCRF $_{12-41}$, LC discharge rate was recorded for at least 6 min before and after the microinfusion. The movement of solution through the calibrated pipette was observed through a microscope throughout the infusion. Injection of the entire volume at this rate usually required 1-2 min.

In experiments designed to determine the effect of CRF or carbachol on LC neurons, discharge rate was recorded for at least 9 min before intracerebroventricularly drug or peptide administration. CRF $[1,3,10$, or $30 \mu \mathrm{g}$ in 3-10 $\mu \mathrm{l}$ artificial CSF (ACSF)] or carbachol $(0.09 \mu \mathrm{g}$ in $3 \mu \mathrm{l}$ ACSF) was injected intracerebroventricularly over a period of $30-45 \mathrm{sec}$, and LC discharge rate was recorded for at least $15 \mathrm{~min}$ after intracerebroventricular administration.

In experiments designed to determine the effect of hypotensive challenge on LC discharge rate, baseline LC discharge rate was recorded for at least $9 \mathrm{~min}$ and then nitroprusside was infused through the intravenous cannula $(0.33 \mathrm{mg} / \mathrm{ml}, 30 \mu \mathrm{l} / \mathrm{min}, 15 \mathrm{~min}$ duration). LC discharge rate and mean arterial blood pressure were continuously recorded during the infusion. Mean arterial blood pressure was monitored with a pressure transducer and amplifier, and the signal was led to a computer via a CED 1401 Plus interface, using Spike 2 software.

For all experiments involving drug administration, only one cell from an individual rat was tested.

Histology. The recording site was marked by intophoresis $(-15 \mu \mathrm{A}, 10$ $\mathrm{min})$ of PSB at the end of the experiment. Neutral red (5 $\mu$ l) was injected through the intracerebroventricular cannula to assure placement in the lateral ventricle. Rats were anesthetized with pentobarbital $(100 \mathrm{mg} / \mathrm{kg}$, i.p.) and perfused with a $10 \%$ solution of paraformaldehyde in phosphate buffer. Brains were removed and cut to visualize neutral red in the ventricular system. They were then stored for at least $24 \mathrm{hr}$ in this solution. Frozen $40-\mu \mathrm{m}$-thick coronal sections cut on a cryostat were mounted on gelatinized glass slides and stained with neutral red for localization of the PSB spot. The data presented are from neurons that were histologically identified as being within the nucleus LC (for review, see Valentino et al., 1983).

Corticosterone and ACTH assay. At the end of the experiments, 1-1.5 $\mathrm{ml}$ of blood was taken from the intravenous cannula into a prechilled microtainer containing EDTA and immediately centrifuged at $3000 \times g$ for $15 \mathrm{~min}$ at $4^{\circ} \mathrm{C}$. Plasma was collected and stored at $-70^{\circ} \mathrm{C}$ until the assay. Corticosterone and $\mathrm{ACTH}$ were assayed by radioimmunoassay (RIA) using an RIA kit from ICN Pharmaceutical (Costa Mesa, CA).

Data analysis. The mean baseline LC spontaneous discharge rate was calculated from three 3 min periods before any treatment (e.g., nitroprusside infusion, drug administration, or sciatic nerve stimulation). PSTH data were analyzed by dividing the histogram into different time components and determining the discharge rate in each component. The first $500 \mathrm{msec}$ represented unstimulated or tonic activity. The evoked response was defined as the period after the stimulus when the LC discharge rate exceeded the mean tonic discharge rate plus $2 \mathrm{SD}$. LC spontaneous discharge rate and different components of the LC sensory response (e.g., tonic discharge, evoked discharge, and signal-to-noise ratio) were compared between adrenalectomized and sham-operated rats by the Student's $t$ test for independent samples. Absolute LC discharge rates after administration of $\mathrm{DPheCRF}_{12-41}$ were compared between groups by the Student's $t$ test for independent samples. Additionally, LC 


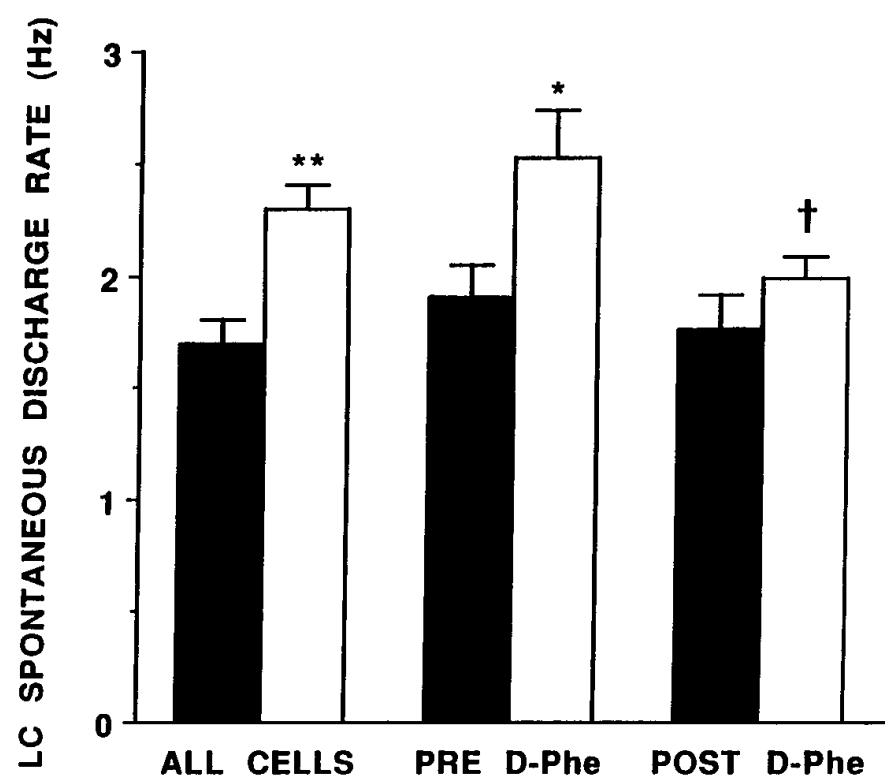

Figure 1. LC spontaneous discharge rate and effects of DPheCRF $\mathrm{D}_{12-41}$ in sham-operated (solid bars) and adrenalectomized (open bars) rats. The ordinate indicates LC discharge rate $(\mathrm{Hz})$. Bars indicate the mean discharge rate for 126 neurons in sham-operated rats and $162 \mathrm{LC}$ neurons in adrenalectomized rats $(A L L C E L L S)$; or eight cells in sham-operated and six cells in adrenalectomized rats before (Pre) and 3 min after (Post) $\mathrm{DPheCRF}_{12-41}$. Vertical lines represent $\pm 1 \mathrm{SEM} ;{ }^{*} p<0.05,{ }^{* *} p<0.001$, $t$ test for independent samples, comparison between sham-operated and adrenalectomized rats; $t p<0.02, t$ test for matched pairs, comparison between Pre and Post.

discharge rate before and after $\mathrm{DPheCRF}_{12-41}$ was compared within groups using the Student's $t$ test for paired observations. The effects of $\mathrm{DPheCRF}_{12-41}$ on the change in LC discharge rate were compared using a one-way ANOVA with repeated measures within groups and a two-way ANOVA for comparisons between groups. The effect of nitroprusside on mean arterial pressure was compared between groups using a two-way ANOVA. The maximum increase in LC discharge rate produced by hypotensive challenge or carbachol administration were compared between groups using the Student's $t$ test for independent samples. Additionally, the effects of nitroprusside on LC discharge were analyzed within groups using a one-way ANOVA with repeated measures and a two-way ANOVA for comparisons between groups. Statistical significance was considered at $p<0.05$.

Drugs. oCRF and DPheCRF 12-41 $_{1}$ were generously supplied by Dr. Jean Rivier (Clayton Foundation Laboratories for Peptide Biology, The Salk Institute, La Jolla, CA). The peptides were dissolved in water to make a $1 \mathrm{mg} / \mathrm{ml}$ solution. Aliquots $(10 \mu \mathrm{l})$ of this solution were concentrated using a Savant Speed Vac concentrator. The $10 \mu \mathrm{g}$ aliquots were stored at $-70^{\circ} \mathrm{C}$ and dissolved in ACSF on the day of the experiment. Sodium nitroprusside (Sigma Chemical, Saint Louis, MO) was dissolved in saline $(0.33 \mathrm{mg} / \mathrm{ml})$ and infused intravenously at a rate of $30 \mu \mathrm{l} / \mathrm{min}$ for $15 \mathrm{~min}$. Carbachol (Sigma) was dissolved in ACSF $(0.03 \mathrm{mg} / \mathrm{ml})$ and administered intracerebroventricularly in a volume of $3 \mu l$.

\section{RESULTS}

\section{LC spontaneous discharge rate and effects of a CRF antagonist}

LC activity was recorded from 126 neurons in 48 sham-operated rats and 162 neurons in 52 adrenalectomized rats. LC spontaneous discharge rate ranged from 0.4 to $3.8 \mathrm{~Hz}$ in sham-operated rats, with a mean rate of $1.7 \pm 0.1 \mathrm{~Hz}$. This is similar to the mean LC discharge rate in intact halothane-anesthetized rats reported in previous studies (Curtis et al., 1994, 1995). LC spontaneous discharge rates of adrenalectomized rats were significantly higher, with a range of $0.5-5.1 \mathrm{~Hz}$, and a mean of $2.3 \pm 0.1 \mathrm{~Hz}$ (Fig. 1).
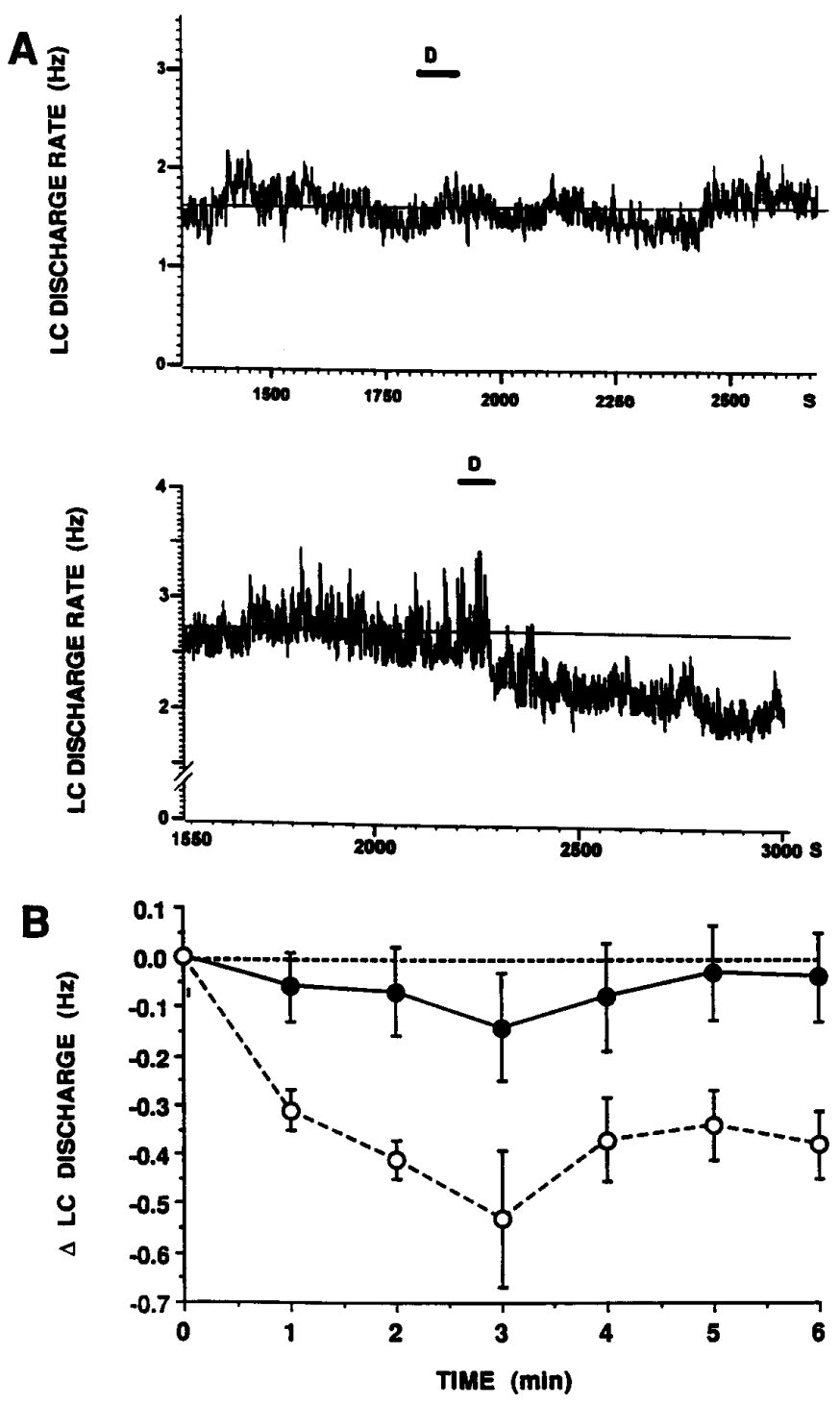

Figure 2. Time course of the effect of $\mathrm{DPheCRF}_{12-41}$. A, Continuous chart record of LC discharge rate before and after intracoerulear infusion of DPheCRF ${ }_{12-41}(10 \mathrm{ng}$ in $30 \mathrm{nl})$. The abscissae indicate time $(s)$. The ordinates indicate LC discharge rate $(\mathrm{Hz})$. The time of infusion is indicated by the bar and $D$ above the traces. The solid horizontal line represents the mean LC discharge rate determined over 6 min before DPheCRF $_{12-41}$ infusion. Top and bottom traces were from single neurons recorded in a sham-operated and adrenalectomized rat, respectively. $B$, Mean effect of DPheCRF ${ }_{12-41}$ in sham-operated (solid symbols, $n=8$ ) versus adrenalectomized rats (open symbols, $n=6$ ). The abscissa indicates time after $\mathrm{DPheCRF}_{12-41}$ infusion. The ordinate indicates the change in LC discharge rate from baseline $(\mathrm{Hz})$. The effects of DPheCRF $\mathrm{F}_{12-41}$ were significantly different in adrenalectomized versus sham-operated rats $\left(F_{(1,97)}=8.3, p<0.02\right)$. Additionally, $\mathrm{DPheCRF}_{12-41}$ significantly decreased LC discharge rate in adrenalectomized $\left(F_{(5,41)}=4.9, p<0.002\right)$ but not sham-operated $\left(F_{(7,55)}=0.72\right)$ rats.

As reported previously in intact rats (Curtis et al., 1994), intracoerulear administration of the CRF antagonist $\mathrm{DPheCRF}_{12-41}$ in a dose that prevents the effects of CRF or hypotensive stress on LC discharge (10 ng in $30 \mathrm{nl}$ ) had no effect on spontaneous LC discharge rates of sham-operated rats (Figs. 1, 2). Figure 2 shows that LC discharge rate remained stable over the time after intracoerulear administration of DPheCRF $\mathrm{F}_{12-41}$. In contrast, intracoerulear administration of this dose of DPheCRF ${ }_{12-41}$ decreased LC discharge rates 


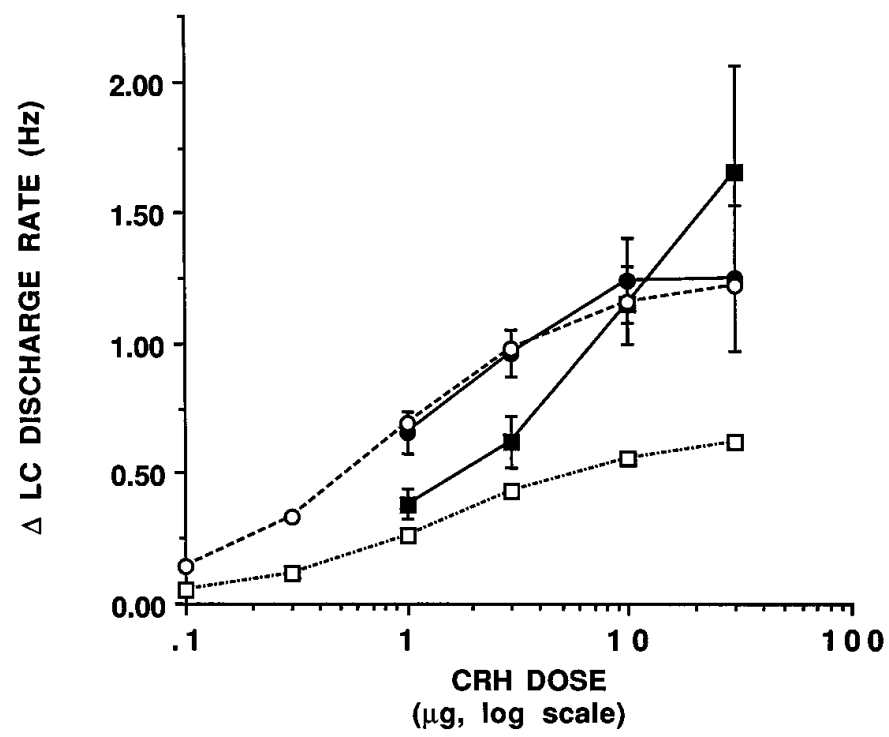

Figure 3. CRF dose-response curves in sham-operated and adrenalectomized rats. The abscissa indicates the dose of CRF (log scale), and the ordinate indicates the increase in LC discharge above pre-CRF rates $(\Delta$ $\mathrm{Hz}$ ). Solid symbols represent experimental data, and open symbols represent theoretical curves. Solid circles show the CRF dose-response curve generated in sham-operated rats. Solid squares represent the experimentally determined CRF dose-response curve in adrenalectomized rats. Each point represents the mean of 4-10 cells, vertical lines represent mean \pm 1 SEM. Open circles represent the theoretical curve based on the equation $\mathrm{E}=E_{\max }[\mathrm{CRF}] / \mathrm{ED}_{50}+[\mathrm{CRF}]$ and assuming that $E_{\max }=1.25$ $\mathrm{Hz}$ and $\mathrm{ED}_{50}=0.82 \mu \mathrm{g}$. Open squares represent the theoretical curve that would be expected in adrenalectomized rats based on additivity, $E=$ $\left(E_{\max }[\mathrm{CRF}+0.8] / K_{\mathrm{d}}+[\mathrm{CRF}+0.8]\right)-0.6$.

of adrenalectomized rats. After $\mathrm{DPheCRF}_{12-41}$, LC discharge rates were similar in adrenalectomized and sham-operated rats (Fig. 1). Figure 2 shows that this effect peaked by 3 min after injection.

\section{LC activation by exogenous CRF}

CRF (1-30 $\mu$ g, i.c.v.) increased LC discharge rate in both adrenalectomized and sham-operated rats (Fig. 3), as reported previously in intact rats (Valentino et al., 1983). Because mean spontaneous discharge rates were significantly different in adrenalectomized versus sham-operated rats, the percentage increase in LC discharge rate could not be used as an endpoint of the CRF effect. Rather, effects were compared and dose-response curves were generated using the absolute change in discharge rate as the dependent variable (Fig. 3).

The maximum effect produced by CRF in sham-operated rats was an increase in LC discharge rate of $1.25 \mathrm{~Hz}$ (Fig. 3, solid circles). The $\mathrm{ED}_{50}$ determined by regression analysis was estimated to be $0.82 \mu \mathrm{g}$, similar to that observed in intact rats (Curtis et al., 1996). The CRF dose-response curve generated in adrenalectomized rats was shifted to the right of that generated in sham-operated rats with a somewhat steeper slope ( 0.9 vs 0.6 , respectively) and approached a higher maximum response (Fig. 3, solid squares).

Because the results presented in Figures 1 and 2 suggested that $\mathrm{CRF}$ was tonically released in adrenalectomized rats, it was predicted that a proportion of CRF receptors were occupied before $\mathrm{CRF}$ administration, and addition of exogenous CRF would result in an additive effect. Therefore, the experimental dose-response curves generated in sham-operated and adrenalectomized rats were compared with the theoretical dose-response curves that would be predicted on the basis of no previous occupancy or additivity, respectively. The theoretical curve for sham-operated rats shown in Figure 3 was based on the equation $E=E_{\max }$ $[\mathrm{CRF}] / \mathrm{ED}_{50}+[\mathrm{CRF}]$, where $E_{\text {max }}=1.25$ and the $\mathrm{ED}_{50}=0.82$ $\mu \mathrm{g}$. As expected, the CRF dose-effect curve generated in shamoperated rats coincided well with the predicted dose-response curve (Fig. 3, cf. solid circles-solid line vs open circles-dashed line). The theoretical dose-effect curve predicted for additivity was generated based on the assumption that the difference in baseline discharge rates between adrenalectomized and sham-operated rats $(0.6 \mathrm{~Hz}$, see Fig. 1$)$ corresponded to a dose of $\sim 0.8 \mu \mathrm{g} \mathrm{CRF}$. The predicted effect of this dose addition is to shift the curve upward for low doses of CRF and approach the same maximum effect. Subtraction of the baseline effect $(0.6 \mathrm{~Hz})$ from all points of this curve yielded the predicted dose-effect curve in adrenalectomized rats based on additivity (Fig. 3, open squares-dashed line). This curve is shifted downward with a decreased maximum response from both the actual (solid circles-solid line) and theoretical (open circles-dashed line) dose-effect curves for shamoperated rats. In adrenalectomized rats, the effect of lower doses of CRF ( 1 and $3 \mu \mathrm{g}$ ) fell on the curve predicted by additivity (cf. solid squares-solid line vs open squares-dashed line). In contrast, administration of 10 and $30 \mu \mathrm{g}$ produced effects that were much greater than would be predicted on the basis of additivity (Fig. 3).

To determine whether the enhanced effects of high doses $(10$ and $30 \mu \mathrm{g}$ ) of intracerebroventricularly administered CRF in adrenalectomized rats were attributable to alterations within or outside of the LC, the effects of a near maximally effective dose of intracoerulearly administered CRF (30 ng) (Curtis et al., 1996) were compared in sham-operated $(n=9)$ and adrenalectomized $(n=9)$ rats. Mean LC discharge rates before local microinfusion of CRF in the LC were $2.2 \pm 0.3 \mathrm{~Hz}$ and $1.6 \pm 0.3 \mathrm{~Hz}$ for adrenalectomized and sham-operated rats, respectively. As was observed after intracerebroventricular administration of $30 \mu \mathrm{g}$ $\mathrm{CRF}$, intracoerulear administration of $30 \mathrm{ng} \mathrm{CRF}$ tended to be more effective in adrenalectomized rats, increasing LC discharge rate by $1.6 \pm 0.2 \mathrm{~Hz}$ versus $1.0 \pm 0.3 \mathrm{~Hz}$, but this apparent difference was not statistically significant $(p=0.12)$. Importantly, on the basis of additivity alone, this dose would be predicted to be less effective in adrenalectomized rats.

\section{LC activation by endogenous CRF (hypotensive challenge)}

Baseline mean arterial blood pressure was similar in adrenalectomized versus sham-operated rats $(84 \pm 2 \mathrm{mmHg}$ and $87 \pm 2$ $\mathrm{mmHg}$, respectively) (Fig. $4 \mathrm{~B}$ ). The time course and magnitude of hypotension produced by intravenous infusion of nitroprusside were not different in adrenalectomized versus sham-operated rats (Fig. 4B). Consistent with previous reports in intact rats (Valentino and Wehby, 1988), this hypotensive challenge was temporally correlated with an increase in LC discharge rate in both sham-operated and adrenalectomized rats (Fig. 4A), and the magnitude of the increase in LC discharge rate was similar in both groups (Fig. 4A). In sham-operated rats, hypotensive challenge was approximately as effective as $1 \mu \mathrm{g}$ CRF $(0.72 \mathrm{~Hz}$ increase in LC discharge rate) (see Fig. $3 B$ ). In contrast, this same challenge produced an effect equivalent to a dose of $4 \mu \mathrm{g}$ CRF $(0.78 \mathrm{~Hz}$ increase in discharge rate) in adrenalectomized rats.

\section{LC activation by an excitatory amino acid input and a muscarinic agonist}

The pattern of LC discharge in response to repeated sciatic nerve stimulation, which activates the LC via excitatory amino acid 


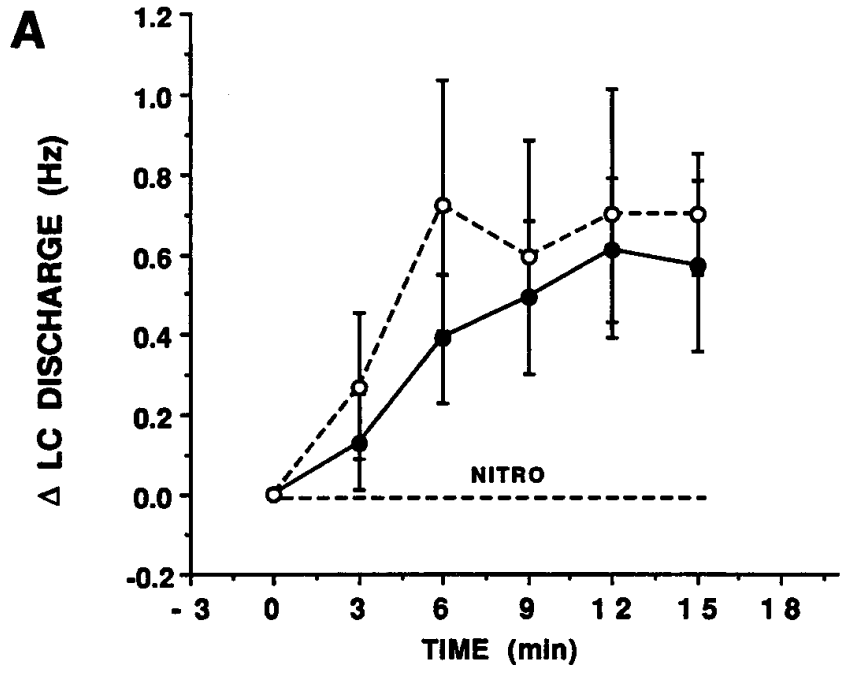

B

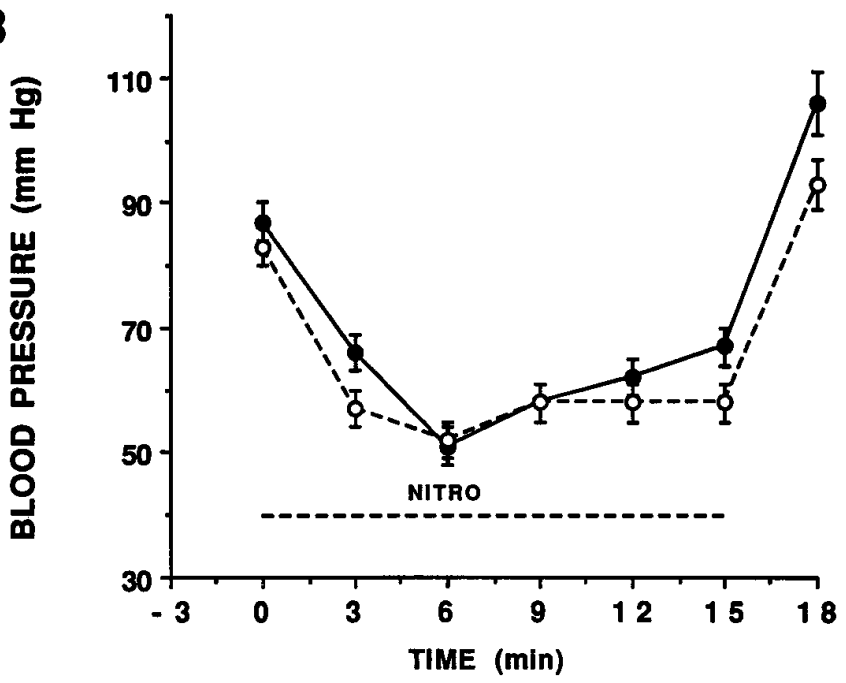

Figure 4. Effect of hypotensive challenge on LC discharge rate and mean arterial blood pressure in sham-operated (solid circles) and adrenalectomized (open circles) rats. The abscissae indicate time ( $\mathrm{min}$ ). Nitroprusside was administered from 0 to $15 \mathrm{~min}$, as indicated by the bar above the abscissae. $A$, The ordinate indicates the change in LC discharge rate above the baseline rate determined over 9 min before nitroprusside infusion. Each point is the mean of at least five rats. Vertical lines represent \pm 1 SEM. Hypotensive challenge increased LC discharge rates in both adrenalectomized and sham-operated rats $\left(F_{(5,41)}=4.9, p<0.001\right.$ and $F_{(4,29)}$ $=6.7, p<0.01$, respectively), and the magnitude of the increase was not different $\left(F_{(1,9)}=0.15\right)$. Mean LC discharge rates before nitroprusside infusion were $1.5 \pm 0.2$ and $3.1 \pm 0.4$ for sham-operated and adrenalectomized rats, respectively. $B$, The ordinate indicates mean arterial blood pressure $(\mathrm{mm} \mathrm{Hg})$. The magnitude of hypotension produced by nitroprusside infusion was similar in adrenalectomized and sham-operated rats $\left(F_{(1,101)}=2.06, p=0.17\right)$.

inputs (Ennis and Aston-Jones, 1988, Ennis et al., 1992), was similar in adrenalectomized and sham-operated rats in this study, as reported in intact rats in previous studies (Valentino and Foote, 1987). Thus, sciatic nerve stimulation was associated with an increase in LC discharge and was followed by a period of relatively inhibited activity. Like LC spontaneous discharge rate, tonic LC discharge rate determined during the unstimulated pe-
A

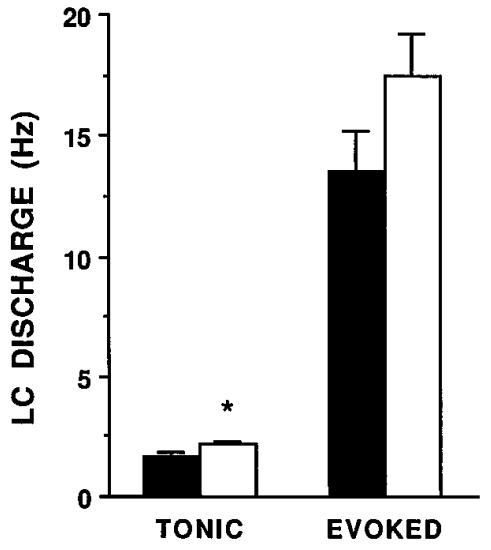

B

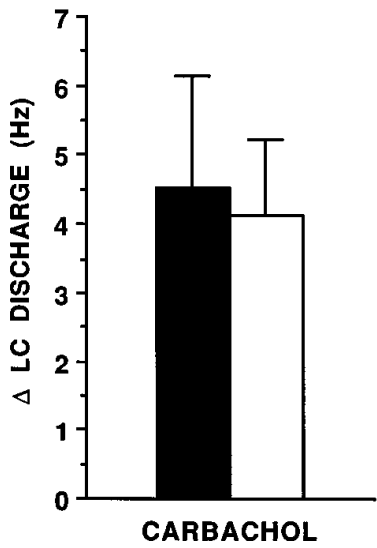

Figure 5. LC activation by sciatic nerve stimulation $(A)$ and carbachol $(B)$ in sham-operated (solid bars) versus adrenalectomized (open bars) rats. $A$, The ordinate represents LC discharge rate $(\mathrm{Hz})$. Bars represent the mean rate during the tonic and evoked components of the $\mathrm{LC}$ response to repeated sciatic nerve stimulation for 21 neurons of sham-operated and adrenalectomized rats. Vertical lines represent mean \pm 1 SEM ${ }^{*} p<0.05$, $t$ test for independent samples. $B$, The ordinate indicates the increase in LC discharge rate above the mean discharge rate determined over 9 min before carbachol $(0.09 \mu \mathrm{g}$, i.c.v. $)$ administration. Bars are the mean of eight rats in both sham-operated and adrenalectomized groups. Carbachol produced a similar increase in LC discharge rate in both groups of rats $(t$ test, independent samples). The mean LC discharge rates before carbachol administration were $1.6 \pm 0.2$ and $2.4 \pm 0.4 \mathrm{~Hz}$ for sham-operated and adrenalectomized rats, respectively.

riod of the trial was significantly higher in adrenalectomized $(2.2 \pm 0.2 \mathrm{~Hz})$ versus sham-operated rats $(1.6 \pm 0.2 \mathrm{~Hz})($ Fig. $5 A)$. However, the evoked LC discharge rates were comparable in both groups (Fig. 5A). Additionally, the ratio of evoked-to-tonic discharge (signal-to-noise ratio) of the sensory response was similar in the two groups (data not shown).

Like CRF, carbachol, administered in a dose that was shown previously to be submaximal in increasing LC discharge rate (Valentino and Aulisi, 1987), significantly increased LC discharge rates of both adrenalectomized and sham-operated rats (Fig. 5B). However, in contrast to $\mathrm{CRF}$, carbachol produced a comparable increase in LC discharge rates of adrenalectomized and shamoperated rats (Fig. 5B).

\section{Effects of adrenalectomy on plasma corticosterone and $\mathrm{ACTH}$}

Plasma corticosterone levels determined at the end of experiments were below the limit of detection in adrenalectomized rats. The mean plasma corticosterone level of the pooled group of sham-operated rats was $263 \pm 27 \mathrm{ng} / \mathrm{ml}$. As reported previously (Bradbury et al., 1991), plasma ACTH levels were greater in the pooled group of adrenalectomized $(1.66 \pm 0.04 \mathrm{ng} / \mathrm{ml})$ versus sham-operated rats $(0.68 \pm 0.006 \mathrm{ng} / \mathrm{ml})$.

\section{DISCUSSION}

The present study demonstrated elevated LC spontaneous discharge rates in adrenalectomized rats and a reversal of this effect after intracoerulear microinfusion of a CRF antagonist. Additionally, the CRF dose-response curve was shifted in adrenalectomized rats in a manner that suggested that a proportion of CRF receptors were occupied before CRF administration. Finally, in adrenalectomized rats, LC responses to hypotensive stress were greater than would be predicted on the basis of additivity. These 
results support the hypothesis that adrenalectomy increases tonicand stress-elicited CRF release in the LC. Because LC activation by a muscarinic agonist or an excitatory amino acid input was not altered by adrenalectomy, the changes produced by adrenalectomy may be selective for LC-CRF interactions. Taken together with studies demonstrating increased synthesis and release of neurohormone CRF after adrenalectomy (Paull and Gibbs, 1983; Plotsky and Sawchenko, 1987; Bradbury et al., 1991; Dallman et al., 1992), the present results suggest that the neurohormone action of CRF and its putative neurotransmitter actions in the LC may be regulated in parallel.

The interpretation that elevated LC discharge rates in adrenalectomized rats result from increased CRF release relies on the selectivity of $\mathrm{DPheCRF}_{12-41}$ as a CRF antagonist. Our previous studies support this selectivity, because DPheCRF $\mathrm{F}_{12-41}$ antagonized LC activation by CRF and hypotensive challenge but not LC activation by sciatic nerve stimulation (Curtis et al., 1994), which has been shown to be mediated by excitatory amino acid inputs to the LC (Ennis and Aston-Jones, 1988; Ennis et al., 1992). Conversely, excitatory amino acid antagonists were ineffective as antagonists of hypotensive challenge (Valentino et al., 1991). Taken together with the finding that LC discharge rates are consistently higher in adrenalectomized versus sham-operated rats, the antagonist study strongly supports the hypothesis that CRF is tonically released within the LC of adrenalectomized but not shamoperated rats, resulting in elevated spontaneous discharge rates.

The shift in the CRF dose-response curve produced by adrenalectomy, which for low doses was consistent with additivity and previous occupancy of a proportion of CRF receptors, supports the above hypothesis. A shift to the right in the CRF dose-effect curve in adrenalectomized rats could be associated with a decrease in postsynaptic sensitivity to CRF. Given the high concentration of corticosteroid receptors in the LC (Harfstrand et al., 1986), the potential for adrenalectomy producing such postsynaptic changes cannot be ruled out. However, taken together with the consistently higher LC discharge rates, the effects of the CRF antagonist, the different slope of the dose-response curve generated in adrenalectomized rats, and the greater apparent maximum effect, the adrenalectomyassociated shift in the CRF dose-response curve is more likely the result of a combination of additivity (at low doses of CRF) and a novel effect of higher doses of CRF (discussed below).

Studies using other endpoints of LC activation are consistent with the hypothesis that the LC-noradrenergic system is tonically activated in adrenalectomized rats. Thus, increased norepinephrine turnover in brain regions innervated by the LC (Javoy et al., 1968), increased tyrosine hydroxylase (TH) expression in LC neurons (measured by immunoblot), and elevated levels cAMPdependent protein kinase (which co-varies with $\mathrm{TH}$ expression) have been reported in adrenalectomized rats (Melia et al., 1992). However, other studies measuring TH mRNA in LC neurons or activity of TH (as measured by DOPA accumulation) have reported a lack of effect of adrenalectomy (Smith et al., 1991; Lachuer et al., 1992). LC discharge rate may be a more sensitive and direct measure of activation. A recent study showed that LC discharge rates recorded $2 \mathrm{~d}$ after adrenalectomy tended to be elevated, consistent with the present findings, although the effect was not statistically significant at this time (Borsody and Weiss, 1996). It is likely that the cellular changes involved in the effects reported in the present study require a longer period of glucocorticoid absence to be fully expressed.

The effects of adrenalectomy on LC spontaneous discharge imply that the CRF that activates the LC is negatively regulated by circulating adrenal steroids. Because glucocorticoid administration does not alter LC activity of intact rats, as indicated by spontaneous discharge rate (Valentino and Wehby, 1988, 1989), TH level, or cAMP-dependent protein kinase levels in the LC (Melia et al., 1992), it is possible that corticosteroid receptors on CRF afferents to the LC are sufficiently occupied by endogenous ligand to mask any effect of additional corticosteroid. Thus, in intact rats, tonic secretion of the CRF, which impacts on the LC, is inhibited, and CRF antagonists have no effect on LC discharge rate, as we have observed in intact rats in previous studies (Valentino et al., 1991; Page et al., 1992, 1993; Curtis et al., 1994) and in sham-operated rats in the present study. These observations suggest a role for type 1 (high-affinity), as opposed to type 2 (low-affinity), corticosteroid receptors in the regulation of CRF release in the LC.

The CRF that is responsible for tonic LC activation in adrenalectomized rats could arise from the ventricular system (possibly as a source of neurohormone CRF) or from CRF terminals in the $\mathrm{LC}$ region (neurotransmitter $\mathrm{CRF}$ ). A diurnal rhythm of CSF CRF levels has been reported (Owens et al., 1990), but the source of this CRF and the effects of adrenalectomy on CSF CRF are unknown. However, to account for the change in LC discharge rate produced by adrenalectomy in this study, the CSF CRF level would have to be in the range of $1.6 \mu \mathrm{g} / \mathrm{ml}(0.8 \mu \mathrm{g}$ in $500 \mu \mathrm{l}$ of CSF in the rat ventricular system). Because this concentration is much greater than that measured in the median eminence, even after stress (e.g., $<1 \mathrm{ng} / \mathrm{ml}$ ) (Plotsky and Vale, 1984), the possibility that $\mathrm{CRF}$ activating the $\mathrm{LC}$ in adrenalectomized rats arises from the CSF is unlikely. Because CRF-immunoreactive terminals have been visualized in the LC (Swanson et al., 1983; Sakanaka et al., 1987; Valentino et al., 1992) and synapses demonstrated between CRF-immunoreactive terminals and LC dendrites (Van Bockstaele et al., 1996), it is more likely that the source of CRF activating the LC in this study is from terminals within the LC. The neuronal origin of these terminals and probable sites of corticosteroid regulation are unknown at this time.

LC activation by hypotensive challenge is thought to be mediated by CRF release in the $\mathrm{LC}$, because it is prevented by intracoeruleuar administration of doses of CRF antagonists that do not alter LC activation by other stimuli (Valentino et al., 1991; Curtis et al., 1994). In the present study, the magnitude of LC activation by hypotensive challenge in sham-operated rats was similar to that produced by $1 \mu \mathrm{g}$ CRF administered intracerebroventricularly. Based on the CRF dose-response curve generated in adrenalectomized rats, this same challenge would be predicted to produce a much smaller increase in LC discharge rate. However, the effect produced by this stimulus in adrenalectomized rats was equivalent to $4 \mu \mathrm{g}$ of CRF. These results suggest that in addition to increasing tonic CRF release, adrenalectomy also results in higher stress-evoked CRF release in the LC. This is consistent with increased pituitary response to stressors in adrenalectomized rats (Rivier and Vale, 1987).

The response of LC neurons to high doses of CRF (10 and 30 $\mu \mathrm{g})$ observed in adrenalectomized rats was not predicted on the basis of simple additivity. At these doses, the CRF dose-response curve became steeper, and the apparent maximum effect was greater than predicted. Possible explanations for this include activation of multiple CRF receptors in the LC or activation of other excitatory inputs to the LC by intracerebroventricularly administered CRF. The finding that similar results were obtained with intracoerulear administration of a near-maximal dose of 
CRF argues against the latter possibility. The possibility that adrenalectomy unmasks an additional effect of CRF on LC neurons that occurs at high doses requires additional investigation.

That LC responses to CRF are selectively altered by adrenalectomy is suggested by the findings that LC responses to sciatic nerve stimulation and a muscarinic agonist were not different in sham-operated versus adrenalectomized rats. In intact rats, LC activation by these stimuli is thought to be mediated solely by excitatory amino acid receptors or muscarinic receptors, respectively (Enberg and Svensson, 1980; Ennis and Aston-Jones, 1988; Ennis et al., 1992). Although it is possible that adrenalectomy alters LC responses to these stimuli such that CRF now plays a role in the mediation of these effects, the present findings showing similar responses in sham-operated versus adrenalectomized rats argue against this possibility.

The implication from these results that a putative neurotransmitter action of CRF is regulated in a similar manner as the neurohormone action of CRF is intriguing, because these actions have been thought to be either insensitive to regulation or regulated differentially. For example, glucocorticoid manipulation altered pituitary but not brain CRF receptors (Wynn et al., 1984; Hauger et al., 1987), and adrenalectomy affected CRF mRNA levels in paraventricular hypothalamic neurons only (Imaki et al., 1991). In other studies, glucocorticoids reduced CRF mRNA in paraventricular hypothalamic neurons and increased CRF mRNA in amygdala neurons (Swanson and Simmons, 1989; Makino et al., 1994). In contrast, evidence exists for a facilitation of both CRF neurohormone activity (Dallman et al., 1992) and CRF neurotransmitter effects in the LC (Curtis et al., 1995) in repeatedly stressed rats. Thus, both adrenalectomy and a previous history of stress may similarly co-regulate both CRF systems.

Parallel regulation of pituitary and LC activation by CRF has important clinical implications. Dysfunctions in the regulation of neurohormone CRF have been implicated in neuroendocrine disorders that accompany depression (Gold et al., 1988). Consistent with this, evidence exists for hypersecretion of neurohormone CRF in depressed subjects (Nemeroff et al., 1984). Hypersecretion of CRF in the LC could underlie some of the cognitive symptoms of depression, such as disturbances of sleep and attention. Importantly, this proposed parallel regulation may explain the coexistence of neuroendocrine and cognitive symptoms in depression.

\section{REFERENCES}

Akaoka H, Aston-Jones G (1991) Opiate withdrawal-induced hyperactivity of locus coeruleus neurons is substantially mediated by augmented excitatory amino acid input. J Neurosci 11:3830-3839.

Bartanusz V, Jezova D, Bertini LT, Tilders FJH, Aubry JM, Kiss JZ (1993) Stress-induced increase in vasopressin and corticotropinreleasing factor expression in hypophysiotropic paraventricular neurons. Endocrinology 132:895-902.

Borsody MK, Weiss JM (1996) Influence of corticotropin-releasing hormone on electrophysiological activity of locus coeruleus neurons. Brain Res 724:149-168.

Bradbury MJ, Akana SF, Cascio CS, Levin N, Jacobson L, Dallman MF (1991) Regulation of basal ACTH secretion by corticosterone is mediated by both type I (MR) and type II (GR) receptors in rat brain. J Steroid Biochem Mol Biol 40:133-142.

Britton KT, Lee G, Vale W, Rivier J, Koob GF (1986) Corticotropinreleasing factor (CRF) receptor antagonist blocks activating and "anxiogenic" actions of CRF in the rat. Brain Res 369:303-306.

Brown MR, Fisher LA, Webb V, Vale W, Rivier J (1985) Corticotropinreleasing factor: a physiologic regulator of adrenal epinephrine secretion. Brain Res 328:355-357.
Butler PD, Weiss JM, Stout JC, Nemeroff CB (1990) Corticotropinreleasing factor produces fear-enhancing and behavioral activating effects following infusion into the LC. J Neurosci 10:176-183.

Caroleo MC, Pulvirenti L, Arbitrio M, Lopilato R, Nistico G (1993) Evidence that $\mathrm{CRH}$ microinfused into the locus coeruleus decreases cell-mediated immune response in rats. Funct Neurol 8:271-277.

Chappell PB, Smith MA, Kilts CD, Bissette G, Ritchie J, Anderson C, Nemeroff CB (1986) Alterations in corticotropin-releasing factor-like immunoreactivity in discrete rat brain regions after acute and chronic stress. J Neurosci 6:2908-2914.

Curtis AL, Grigoriadis D, Page ME, Rivier J, Valentino RJ (1994) Pharmacological comparison of two corticotropin-releasing factor antagonists: in vivo and in vitro studies. J Pharmacol Exp Ther 268:359-365.

Curtis AL, Pavcovich LA, Grigoriadis DE, Valentino RJ (1995) Prior stress alters corticotropin-releasing factor neurotransmission in the locus coeruleus. Neuroscience 65:541-550.

Curtis AL, Florin-Lechner SM, Pavcovich LA, Valentino RJ 1996 Corticotropin-releasing factor microinfusion into the locus coeruleus: effects on discharge rate cortical norepinephrine levels and cortical electroencephalographic activity. Soc Neurosci Abstr 22:1554.

Dallman MF, Akana SF, Scriber KA, Bradbury MJ, Walker CD, Strack AM, Cascio CS (1992) Stress, feedback and facilitation in the hypothalamo-pituitary-adrenal axis. J Neuroendocrinol 4:517-526.

De Goeij DCE, Jezova D, Tilders FJH (1992) Repeated stress enhances vasopressin synthesis in corticotropin releasing factor neurons in the paraventricular nucleus. Brain Res 557:265-268.

DeSouza EB (1987) Corticotropin-releasing factor receptors in the rat central nervous system: characterization and regional distribution. J Neurosci 7:88-100.

DeSouza EB, Insel TR, Perrin MH, Rivier J, Vale WW, Kuhar MJ (1985) Corticotropin-releasing factor receptors are widely distributed within the rat central nervous system: an autoradiographic study. J Neurosci 5:3189-3203.

Dunn AJ, Berridge CW (1990) Physiological and behavioral responses to corticotropin-releasing factor administration: is CRF a mediator of anxiety or stress. Brain Res Rev 15:71-100.

Enberg G, Svensson TH (1980) Pharmacological analysis of a cholinergic receptor mediated regulation of brain norepinephrine neurons. J Neural Transm 49:137-150.

Ennis M, Aston-Jones G (1988) Activation of locus coeruleus from nucleus paragigantocellularis: a new excitatory amino acid pathway in brain. J Neurosci 8:3644-3657.

Ennis M, Aston-Jones G, Shiekhattar R (1992) Activation of locus coeruleus neurons by nucleus paragigantocellularis or noxious sensory stimulation is mediated by intracoerulear excitatory amino acid neurotransmission. Brain Res 598:185-195.

Fink G, Robinson I, Tannahill LA (1988) Effects of adrenalectomy and glucocorticoids on the peptides corticotropin-releasing factor-41 and oxytocin in rat hypophysial portal blood. J Physiol (Lond) 401:329-345.

Florin SM, Curtis AL, Valentino RJ (1995) Role of corticotropinreleasing hormone and excitatory amino acids in locus coeruleus activation by colonic distention. Soc Neurosci Abstr 21:359.

Gold PW, Goodwin FK, Chrousos GP (1988) Clinical and biochemical manifestations of depression: relation to the neurobiology of stress. N Engl J Med 319:413-420.

Harfstrand A, Fuxe K, Cintra A, Agnati LF, Zini I, Wikstrom A-C, Okret S, Yu Z-Y, Goldstein M, Steinbusch H, Verhofstad A, Gustafsson H-A (1986) Glucocorticoid receptor immunoreactivity in monoaminergic neurons of rat brain. Proc Natl Acad Sci USA 83:9779-9783.

Hauger RL, Millan MA, Catt KJ, Aguilera G (1987) Differential regulation of brain and pituitary corticotropin-releasing factor receptors by corticosterone. Endocrinology 120:1527-1533.

Imaki T, Nahan JL, Sawchenko PE, Vale W (1991) Differential regulation of corticotropin-releasing factor mRNA in rat brain regions by glucocorticoids and stress. J Neurosci 11:585-599.

Javoy F, Glowinski J, Kordon C (1968) Effects of adrenalectomy on the turnover of norepinephrine in the rat brain. Eur J Pharmacol 4:103-104.

Jingami H, Matsukura S, Numa S, Imura H (1985) Effects of adrenalectomy and dexamethasone administration on the level of preprocorticotropin-releasing factor mRNA in the hypothalamus and adrenocorticotropin/B-lipotropin precursor mRNA in the pituitary in rats. Endocrinology 117:1314-1320.

Kalin NH, Sherman JE, Takahashi LK (1988) Antagonism of endogenous corticotropin-releasing hormone systems attenuates stress-induced freezing behaviors in rats. Brain Res 457:130-135. 
Lachuer J, Buda M, Tappaz M (1992) Differential time course activation of the brain stem catecholaminergic groups following chronic adrenalectomy. Neuroendocrinology 56:125-132.

Lavicky J, Dunn AJ (1993) Corticotropin-releasing factor stimulates catecholamine release in hypothalamus and prefrontal cortex in freely moving rats as assessed by microdialysis. J Neurochem 60:602-612.

Makino S, Gold PW, Schulkin J (1994) Corticosterone effects on corticotropin-releasing hormone mRNA in the central nucleus of the amygdala and the parvocellular region of the paraventricular nucleus of the hypothalamus. Brain Res 640:105-112.

Mamalaki E, Kvetnansky R, Brady LS, Gold PW, Herkenham M (1992) Repeated immobilization stress alters tyrosine hydroxylase, corticotropin-releasing hormone and corticosteroid receptor messenger ribonucleic acid levels in rat brain. J Neuroendocrinol 4:689-699.

Melia KR, Rasmussen K, Terwiliger RZ, Haycock JW, Nestler EJ, Duman RS (1992) Coordinate regulation of cyclic AMP system with firing rate and expression of tyrosine hydroxylase in the rat locus coeruleus: effects of chronic stress and drug treatments. J Neurochem 58:494-502.

Monnikes H, Schmidt BG, Tebbe J, Bauer C, Tache Y (1994) Microinfusion of corticotropin-releasing factor (CRF) into the locus coeruleus/ subcoeruleus nuclei stimulates colonic motor function in rats. Brain Res 644:101-108.

Nemeroff CB, Widerlov E, Bissette GT, Walleus H, Karlson I, Eklund K, Kilts C, Loosen P, Vale W (1984) Elevated concentrations of CSF corticotropin-releasing factor-like immunoreactivity in depressed patients. Science 226:1342-1344.

Owens MJ, Bartolome J, Schanberg SM, Nemeroff CB (1990) Corticotropin-releasing factor concentrations exhibit an apparent diurnal rhythm in hypothalamic and extrahypothalamic brain regions: differential sensitivity to corticosterone. Neuroendocrinology 5752:626-631.

Owens MJ, Nemeroff CB (1991) Physiology and pharmacology of corticotropin-releasing factor. Pharmacol Rev 43:425-474.

Page ME, Abercrombie ED (1995) Corticotropin-releasing factor in the locus coeruleus increases extracellular norepinephrine in the rat hippocampus. Soc Neurosci Abstr 21:634.

Page ME, Akaoka H, Aston-Jones G, Valentino RJ (1992) Bladder distention activates locus coeruleus neurons by an excitatory amino acid mechanism. Neuroscience 51:555-563.

Page ME, Berridge CW, Foote SL, Valentino RJ (1993) Corticotropinreleasing factor in the locus coeruleus mediates EEG activation associated with hypotensive stress. Neurosci Lett 164:81-84.

Paull WK, Gibbs FP (1983) The corticotropin-releasing factor (CRF) neurosecretory system in intact, adrenalectomized, and adrenalectomizeddexamethasone treated rats. Histochemistry 78:303-316.

Plotsky PM, Sawchenko PE (1987) Hypophysial-portal plasma levels, median eminence content, and immunohistochemical staining of corticotropin-releasing factor, vasopressin and oxytocin after pharmacological adrenalectomy. Endocrinology 120:1361-1369.

Plotsky PM, Vale W (1984) Hemorrhage-induced secretion of corticotropin-releasing factor-like immunoreactivity into the rat hypophyseal portal circulation and its inhibition by glucocorticoids. Endocrinology 114:164-169.

Rassnick S, Sved AF, Rabin BS (1994) Locus coeruleus stimulation by corticotropin-releasing hormone suppresses in vitro cellular immune responses. J Neurosci 14:6033-6040.

Rivier C, Vale W (1987) Diminished responsiveness of the hypothalamicpituitary-adrenal axis of the rat during exposure to prolonged stress: a pituitary-mediated mechanism. Endocrinology 121:1320-1328.

Rivier C, Bruhn T, Vale W (1985) Effects of corticotropin-releasing factor, neurohypophyseal peptides, and catecholamines on pituitary function. Fed Proc 44:189-195.

Sakanaka M, Shibasaki T, Lederes K (1987) Corticotropin-releasing factor-like immunoreactivity in the rat brain as revealed by a modified cobalt-glucose oxide-diaminobenzidene method. J Comp Neurol 260:256-298.

Sawchenko PE, Swanson LW, Vale WW (1984) Co-expression of corticotropin-releasing factor and vasopressin immunoreactivity in parvocellular neurosecretory neurons of the adrenalectomized rat. Proc Natl Acad Sci USA 81:1883-1887.

Smagin GN, Swiergiel AH, Dunn AJ (1995) Corticotropin-releasing factor administered into the locus coeruleus, but not the parabrachial nucleus, stimulates norepinephrine release in the prefrontal cortex. Brain Res Bull 36:71-76.

Smith MA, Brady LS, Glowa J, Gold PW, Herkenham M (1991) Effects of stress and adrenalectomy on tyrosine hydroxylase mRNA levels in the locus ceruleus by in situ hybridization. Brain Res 544:26-32.

Suda T, Tomori N, Tozawa F, Mouri T, Demura H, Shizume K (1983) Effects of bilateral adrenalectomy on immunoreactive corticotropinreleasing factor in the rat median eminence and intermediate-posterior pituitary. Endocrinology 113:1182-1184.

Swanson LW, Simmons DM (1989) Differential steroid hormone and neural influences on peptide mRNA levels in CRH cells of the paraventricular nucleus: a hybridization histochemical study in the rat. J Comp Neurol 285:413-435.

Swanson LW, Sawchenko PE, Rivier J, Vale W (1983) Organization of ovine corticotropin-releasing factor immunoreactive cells and fibers in rat brain: an immunohistochemical study. Neuroendocrinology 36:165-186.

Swiergel AH, Takahashi LK, Ruben WW, Kalin NH (1992) Antagonism of corticotropin-releasing factor receptors in the locus coeruleus attenuates shock-induced freezing in rats. Brain Res 587:263-268.

Tache Y, Monnikes H, Bonaz B, Rivier J (1993) Role of CRF in stressrelated alterations of gastric and colonic motor function. Ann NY Acad Sci 697:233-243.

Tazi A, Dantzer R, LeMoal M, Rivier J, Vale W, Koob GF (1987) Corticotropin-releasing factor antagonist blocks stress-induced fighting in rats. Reg Peptides 18:37-42.

Vale W, Spiess J, Rivier C, Rivier J (1981) Characterization of a 41residue ovine hypothalamic peptide that stimulates secretion of corticotropin and beta-endorphin. Science 213:1394-1397.

Vale W, Rivier C, Brown MR, Spiess J, Koob G, Swanson L, Bilezikjian L, Bloom F, Rivier J (1983) Chemical and biological characterization of corticotropin-releasing factor. Recent Prog Horm Res 39:245-270.

Valentino RJ, Aulisi E (1987) Carbachol-induced increases in locus coeruleus spontaneous activity are associated with disruption of sensory responses. Neurosci Lett 74:297-303.

Valentino RJ, Foote SL (1987) Corticotropin-releasing factor disrupts sensory responses of brain noradrenergic neurons. Neuroendocrinology 45:28-36.

Valentino RJ, Foote SL (1988) Corticotropin-releasing factor increases tonic but not sensory-evoked activity of noradrenergic locus coeruleus neurons in unanesthetized rats. J Neurosci 8:1016-1025.

Valentino RJ, Wehby RG (1988) Corticotropin-releasing factor: evidence for a neurotransmitter role in the locus coeruleus during hemodynamic stress. Neuroendocrinology 48:674-677.

Valentino RJ, Wehby RG (1989) Locus coeruleus discharge characteristics of morphine-dependent rats: effects of naltrexone. Brain Res 488:126-134.

Valentino RJ, Foote SL, Aston-Jones G (1983) Corticotropin-releasing factor activates noradrenergic neurons of the locus coeruleus. Brain Res 270:363-367.

Valentino RJ, Martin DL, Suzuki M (1986) Dissociation of locus coeruleus activity and blood pressure: effects of clonidine and corticotropinreleasing factor. Neuropharmacology 25:603-610.

Valentino RJ, Page ME, Curtis AL (1991) Activation of noradrenergic locus coeruleus neurons by hemodynamic stress is due to local release of corticotropin-releasing factor. Brain Res 555:25-34.

Valentino RJ, Page ME, Van Bockstaele E, Aston-Jones G (1992) Corticotropin-releasing factor innervation of the locus coeruleus region: distribution of fibers and sources of input. Neuroscience 48:689-705.

Valentino RJ, Foote SL, Page ME (1993) The locus coeruleus as a site for integrating corticotropin-releasing factor and noradrenergic mediation of stress responses. Ann NY Acad Sci 697:173-188.

Van Bockstaele EJ, Colago EEO, Valentino RJ (1996) Corticotropinreleasing factor-containing axon terminals synapse onto catecholamine dendrites and may presynaptically modulate other afferents in the rostral pole of the nucleus locus coeruleus in the rat brain. J Comp Neurol 364:523-534.

Wynn PC, Hauger RL, Holmes MC, Millan MA, Catt KJ, Aguilera G (1984) Brain and pituitary receptors for corticotropin-releasing factor: localization and differential regulation after adrenalectomy. Peptides 5:1077-1084.

Young WS, Mezey E, Siegel RE (1986) Quantitative in situ hybridization histochemistry reveals increased levels of corticotropin-releasing factor mRNA after adrenalectomy in rats. Neurosci Lett 70:198-203. 